\title{
NEW TECHNIQUES FOR SAMPLING AND CONSOLIDATION OF SEDIMENTS: APPLICATION TO BURNT SOILS FROM AN ARCHAEOLOGICAL SITE IN AUSTRIA
}

\author{
E. Aidona ${ }^{1,2}$, R. Scholger ${ }^{2}$ and H. J. Mauritsch ${ }^{2}$ \\ ${ }^{1}$ Geophysical Laboratory, School of Geology, Aristotle University of Thessaloniki, PO Box 352-1, \\ 54006, Thessaloniki, aidona@lemnos.geo.auth.gr, now at: Paleomagnetic Laboratory, Chair of \\ Geophysics, University of Leoben, Austria, elina.aidona@unileoben.ac.at
}

\author{
${ }^{2}$ Paleomagnetic Laboratory, Chair of Geophysics, University of Leoben, Austria, \\ scholger@unileoben.ac.at
}

\section{ABSTRACT}

An archaeomagnetic study requires samples to be oriented very precisely prior to the removal from the site and to be transported safely since most of the times the collected samples are very soft and fragile. In this study we present new techniques for sampling and consolidation of sediments and unconsolidated soils, which are useful tools for palaeomagnetic and archaeomagnetic investigations.

An application of the above techniques has been performed in burnt soils (roastbeds) in an archaeological site near Eisenerz (Austria), which used to be a cooper-smelting place in Bronze Age (around 1450 b.c.) Several roast beds have been collected and consolidated in order to investigate the distribution and the stability of the magnetization of these materials. We obtained around 350 samples and the natural remanent magnetization and the magnetic susceptibility of all these samples have been measured with a $2 \mathrm{G}$ squid cryogenetic magnetometer and a GEOFYSIKA KLY-2 susceptibility meter, respectively.

Plots of the natural remanent magnetization and magnetic susceptibility versus depth indicate different layers of heating and give some first evidences for the use of these soils during the smelting procedure. Higher values of the intensity of the magnetization as well as of the magnetic susceptibility represent the more intense heating layer.

Magnetic cleaning (thermal and Af demagnetization) of pilot samples revealed the presence of a stable component of magnetization.

It seems, therefore, that these types of materials are suitable for an archaeomagnetic investigation, since they are able to record and preserve all the necessary magnetic information and provide important knowledge concerning the recent history of the Earth's magnetic field.

\section{INTRODUCTION}

Archaeomagnetism is based on the determination of the paleodirection and paleointensity of the geomagnetic field using archaeological samples such as baked clays, which have been heated above the Curie temperature (up to $680^{\circ} \mathrm{C}$ ). These clays usually carry a stable magnetization that is almost entirely a thermoremanence, which has 'fossilized' the direction and the intensity of the field at the time and the place of the last heating.

During the last 50 years intensive archaeomagnetic studies enabled the construction of standard curves of the variation of the earth's magnetic field in different regions of Europe, (Kovacheva \&Toshkov 1994, Marton 1996, Kovacheva et al. 1998, Chauvin et al. 2000, Hedley 2001, Schnepp et al 2004). However, most of the studies deal with baked clays (ovens, bricks) since they proved to be very reliable. In this paper we study samples from roast beds, which are very heterogeneous materials, but have been exposed to very high temperatures (up to $1400^{\circ} \mathrm{C}$ ). The main purpose of 
this study was to examine if this kind of materials can be used in an archaeomagnetic study providing reliable results.

The study area is an archaeological site near Eisenerz (Fig. 1a) in Styria which used to be a cooper smelting activity area in Bronze Age. Based on pottery findings, the site was determined as Late Bronze Age, but recent radiocarbon ages predate the smelting activities to Middle Bronze Age at about $1450 \mathrm{BC}$ (Doonan et.al, 1994).

According to Doonan et al. (1994), two types of features were identified that suggested the use of high temperatures in the processing of ores in the area of Eisenerz. The first type of feature was defined by a rectangular structure built of schist blocks. These blocks showed evidence of exposure to high temperatures by the nature of their scorched red color and fire cracked condition. The ground, both in and around these features had been burnt deep red. It is proposed that these structures represent the remains of roasting hearths used for the roasting of sulphidic copper ores (Fig 1b). These features are of similar appearance to those described by Eibner (1982) as Röstbetten or Röststadel. The second type exhibits evidence suggesting that it has been used for the smelting of sulphidic copper ores. These features are essentially rectangular and they were built into a natural terrace.

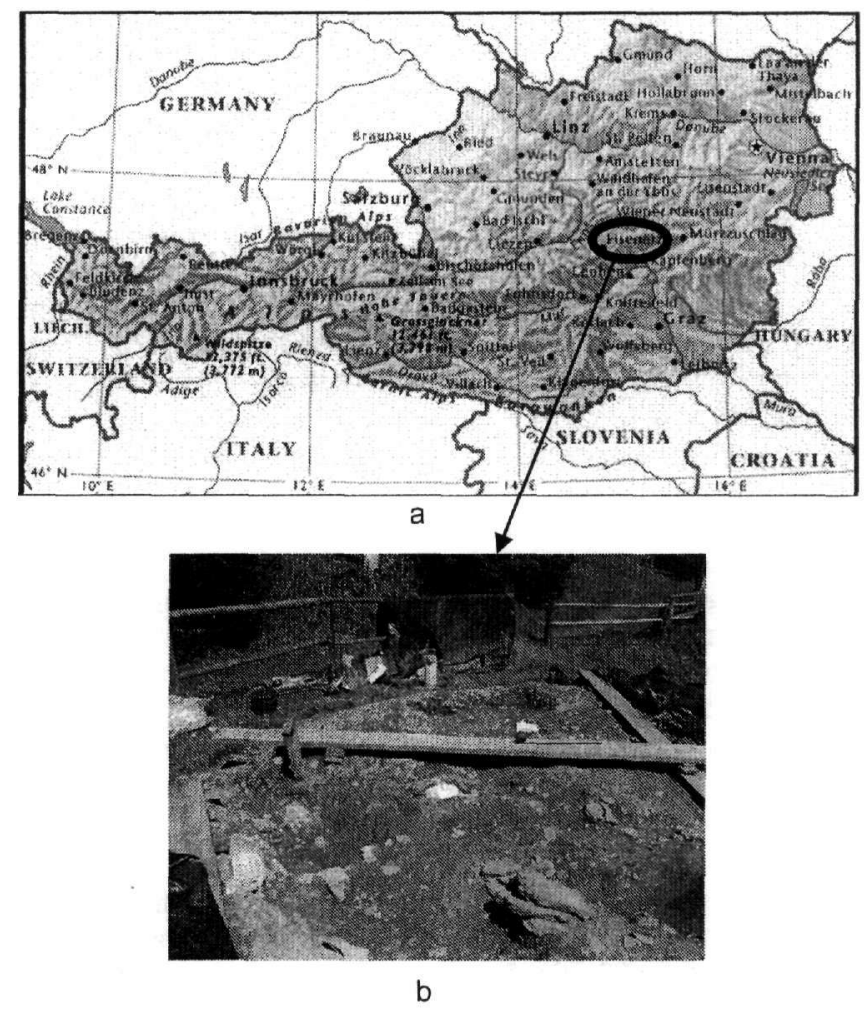

\section{FIGURE 1. LOCATION MAP (A) AND SAMPLING AREA SHOWING THE ROAST BEDS (B).SAMPLING AND CONSOLIDATION}

From the archaeological site 5 different roast beds were sampled for archaeomagnetic investigations. As it is shown in figure 2, we first cut the sample with a saw and isolated it with a cardboard and then covered it with plaster. When the plaster was dry the orientation line was drawn and we removed the samples. In this way all the samples were protected during their transportation to the laboratory since they were very fragile and unconsolidated. 

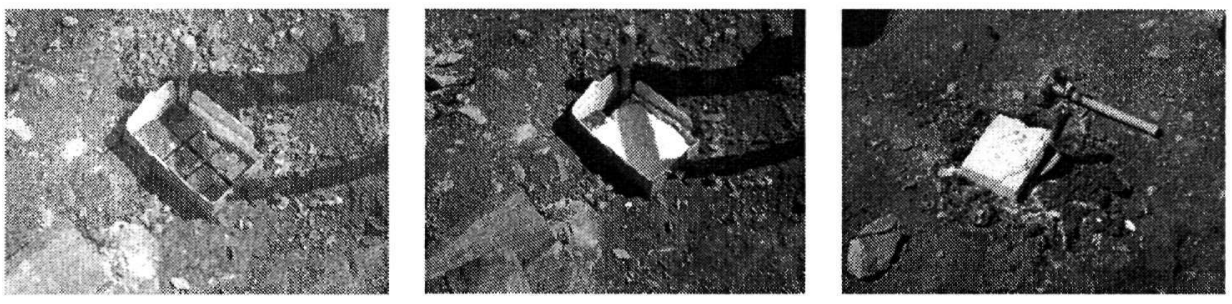

Figure 2. Sampling technique used in this study.

The samples were consolidated in the laboratory using a synthetic resin which called 'Silin Stonehardener' and it is a solvent free hardener on the base of silica-acid-ester". First of all we covered the whole sample with plaster always with respect to the horizontal and then we cut the samples in the middle. We injected the resin several times per day in order to have the best penetration into the samples (Fig. 3). After a few days, when the hardener was dry, we cut the samples in slices and from these slices we prepared cube specimens $(1,8 \times 1,8 \mathrm{~cm})$. We finally obtained around 350 specimens.
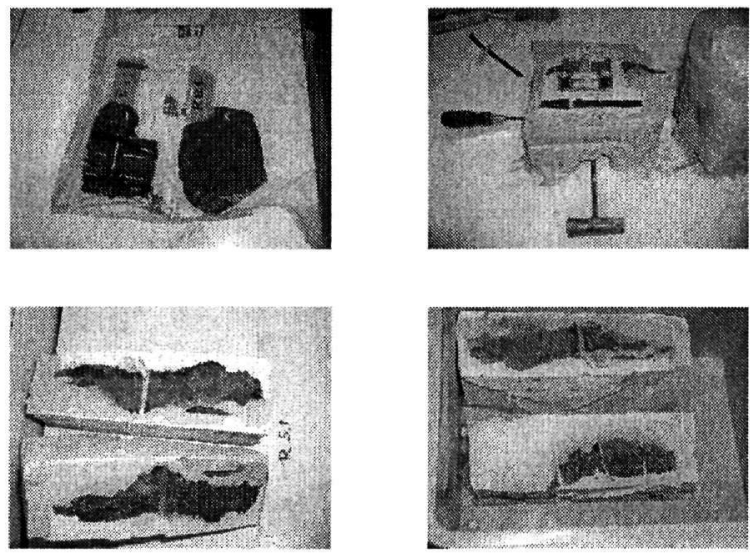

Figure 3. Preparation of specimens in the laboratory and consolidation treatment.

\section{MEASUREMENTS}

The natural remanent magnetization (NRM) and the magnetic susceptibility of all samples have been measured with a $2 G$ squid cryogenetic magnetometer and a GEOFYSIKA KLY-2 susceptibility meter respectively. AF and thermal cleaning (demagnetization) have been performed in specimens in order to determine the characteristic component of their magnetization. Isothermal remanent magnetization (IRM) and thermomagnetic analysis have been performed in pilot samples for the determination of the magnetic carriers. The IRM was imparted using a $2 \mathrm{G}$ pulse magnetizer. The thermomagnetic analyses were performed on a GEOFYSIKA KLY-2 kappabrigde which measures the variation of the magnetic susceptibility with temperature. Finally, the classical Thellier method (Thellier \& Thellier 1959) was used to evaluate the ancient geomagnetic field intensity in selected specimens. 


\section{RESULTS}

\subsection{Distribution of NRM and susceptibility within the samples}

In order to investigate the distribution of the NRM and the susceptibility within the samples we plot these values with depth for all samples (Fig. 4-5). As it is shown in figures 4 and 5 the overall direction of the natural remanent magnetization (black arrows) is reliable and in a very good agreement with the direction of the recent geomagnetic field. The higher values of the intensity of the magnetization as well as of the magnetic susceptibility represent the more intense heating layer, therefore it was expected to observe them in the upper part of our slices. Although these upper parts seem to have high values of intensity and susceptibility they are not the maximum ones. This 'strange' behavior can be explained if we take into account that the upper parts of the samples were exposed to the natural erosion. On the opposite, the higher values are found in a depth of 4$6 \mathrm{~cm}$. Thus, these high values correspond to an older smelting procedure.
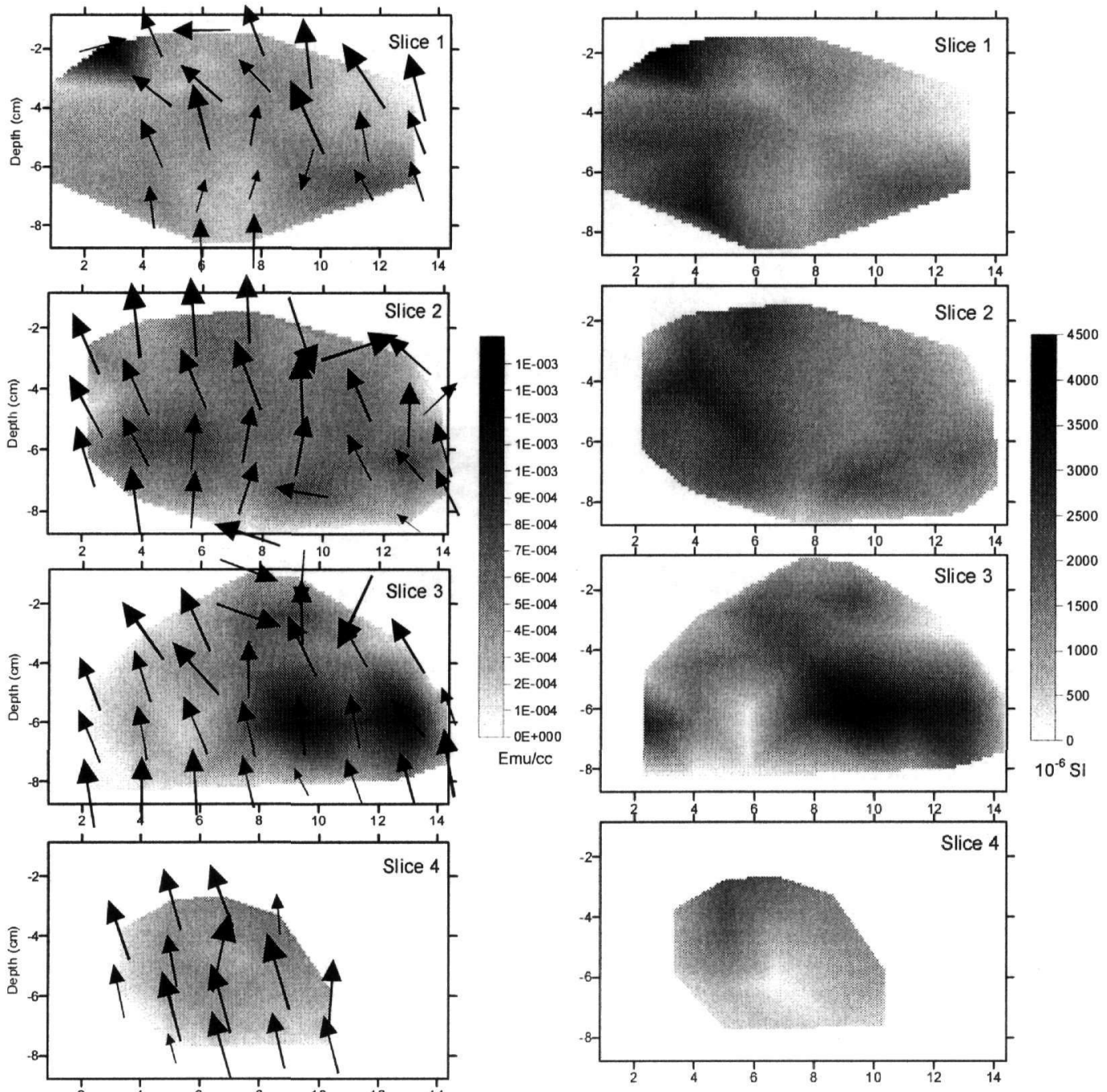

Figure 4. Distribution of NRM (left) and susceptibility (right) of R4 roast bed. Black arrows represent the direction of the NRM . 

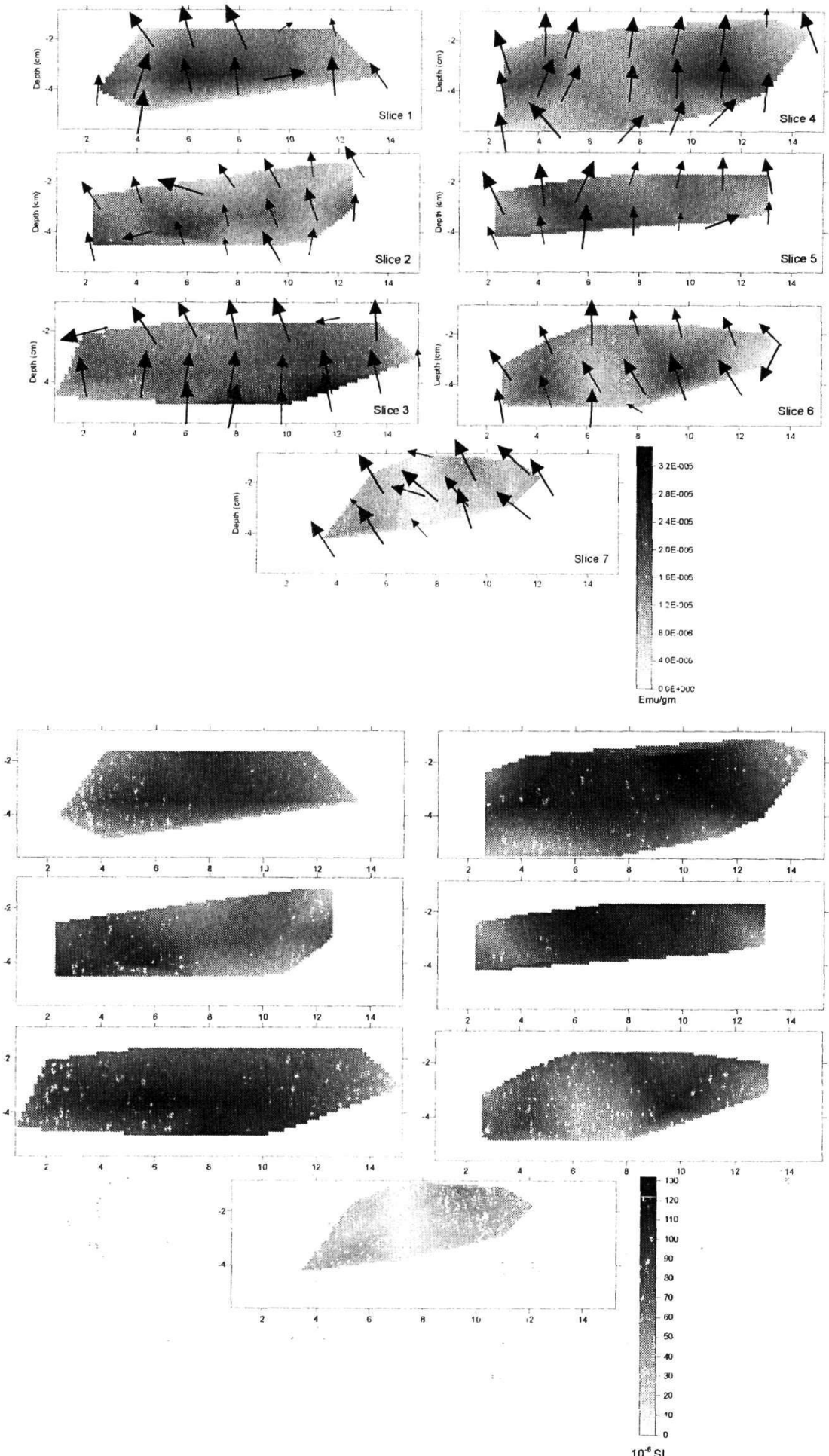

Figure 5. Disiribution of NRM (top) and susceptibility (bottom) of R3.1 roast bed. Black arrows represertt the direction of the NRM. 
The demagnetization process reveals the presence of one stable component of magnetization with the same direction as the natural remanent magnetization as it is shown in figure 6 . The majority of the samples could be demagnetized up to $100 \mathrm{mT}$ or $550^{\circ} \mathrm{C}$. Only in few cases (especially in specimens taken from the upper part of the slices) the demagnetization was not complete even up to $140 \mathrm{mT}$ or $690^{\circ} \mathrm{C}$, indicating the presence of a hard component of magnetization (Fig. 7). This hard component can represent either some portions of heamatite or other iron oxides such as goethite.

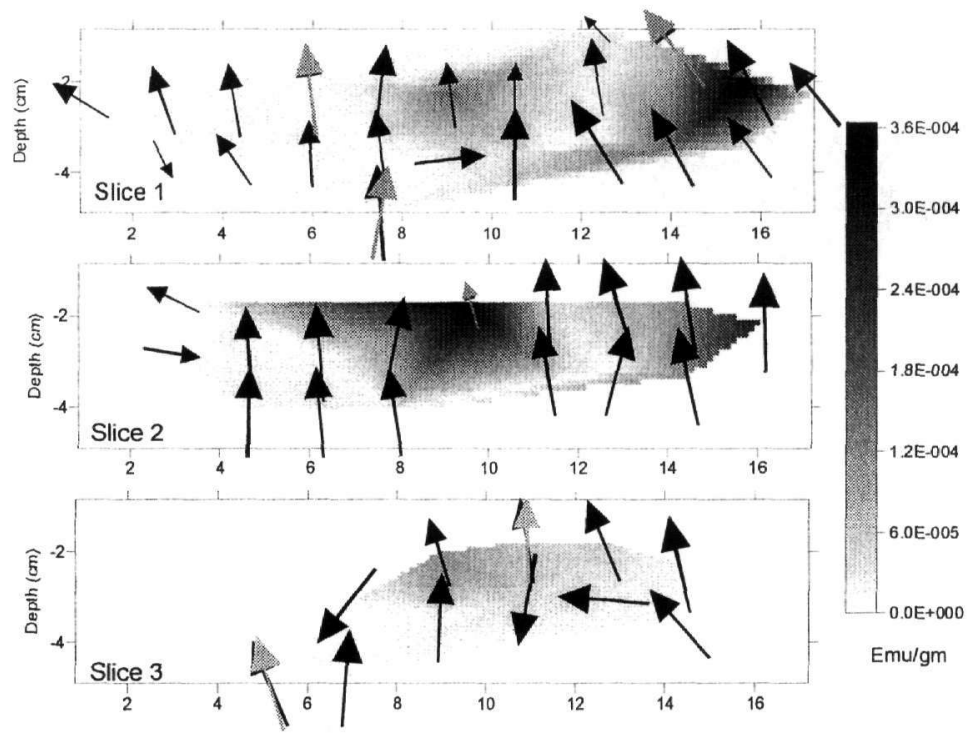

Figure 6. Distribution of intensity and direction of NRM in roast bed R5. Gray arrows indicate the characteristic direction after the demagnetization.
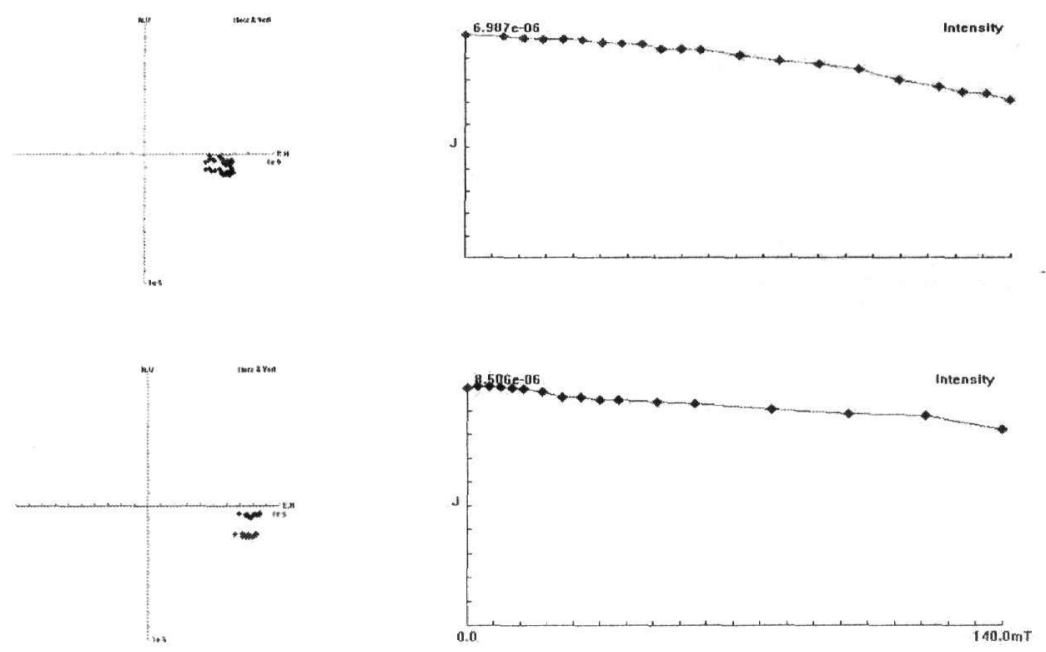

Figure 7. Zijderveld diagrams (left) and intensity decay curves (right) showing that the demagnetization of these specimens is not complete. 


\subsection{Rock magnetism analysis}

Isothermal remanent acquisition curves (IRM) and thermomagnetic analysis have been performed on pilot samples in order to identify the magnetic carriers. IRM measurements revealed the presence of magnetite and hematite as the main magnetic carriers (Fig.8). It is also confirmed by the IRM curves, that a small portion of iron oxides contributes to the magnetization of our samples. This is another sign suggesting that the specimens from the upper part of the roast beds were subjected to weathering since goethite is a characteristic mineral in this kind of environments.

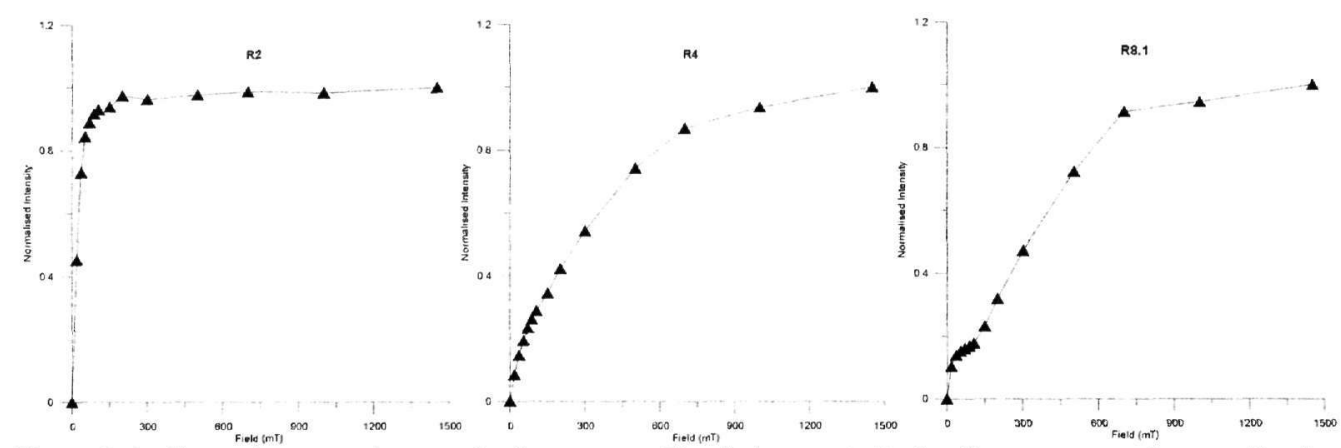

Figure 8. Isothermal remanent magnetization curves. The first curve indicates the presence of magnetite, the second is not saturated up to $1400 \mathrm{mT}$ suggesting the presence of hematite and the third one shows the contribution of the iron oxide goethite.

Thermomagnetic analysis confirms the dominance of magnetite with smaller contributions of heamatite. It is also clear that during the heating, secondary magnetite is formed, as it can be seen from the shifting of the cooling curve (fig.9).
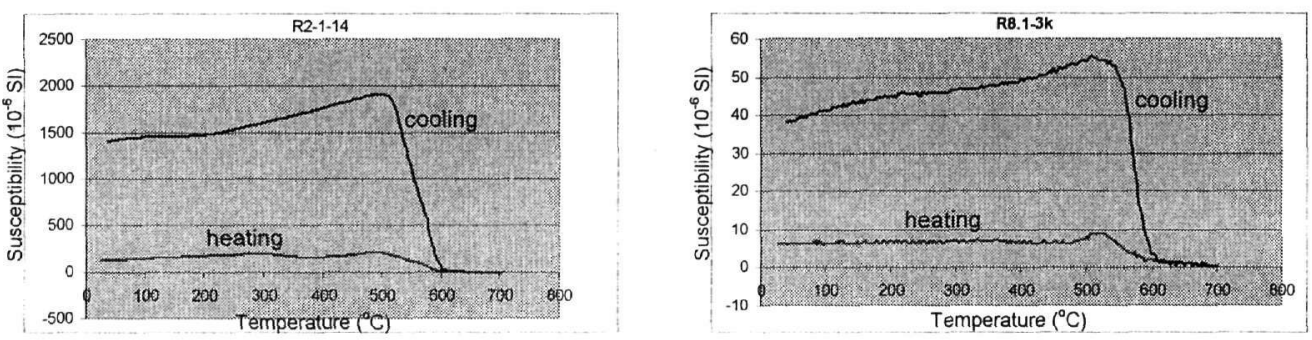

Figure 9. Thermomagnetic analysis of representative samples.

\subsection{Palaeointensity results}

The classical method developed by Thellier \& Thellier (1959) was used for the determination of the ancient geomagnetic field intensity. Although this method is time consuming, it has proved to give reliable results if the materials used are suitable (Kono \& Tanaka1984). The estimation of the ancient intensity $\mathrm{F}^{\mathrm{A}}$, is determined from the relationship:

$$
F^{A}=b \cdot F_{l a b}
$$

and thus is dependent on the slope (b) of the line formed by plotting experimentally obtained decreasing values of NRM against increasing values of laboratory induced TRM. This kind of plots are so-called Arai diagrams (Nagata et al. 1963).

Several specimens from the 5 roastbeds were used for the paleointensity determination using a laboratory field of $50 \mu \mathrm{T}$. In figure 10, characteristic results from 2 different roast beds are shown, using for their reliability the criteria proposed by Aitken et al. (1986). Although the Arai plots are 
successful, the calculated paleointensities are lower than the expected value $(\sim 50 \mu T)$. This fact also suggests that part of the magnetization of these samples was destroyed and, thus, during the Thellier experiment they can not acquire the whole amount of magnetization.

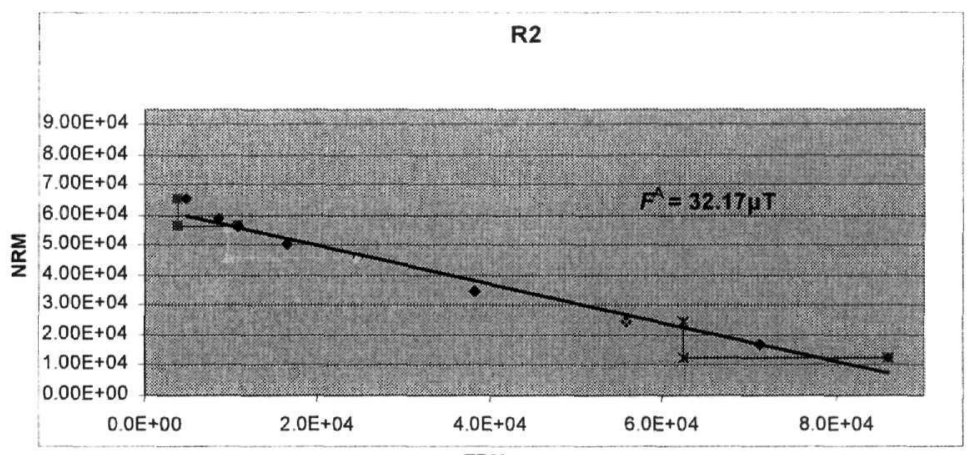

TRM

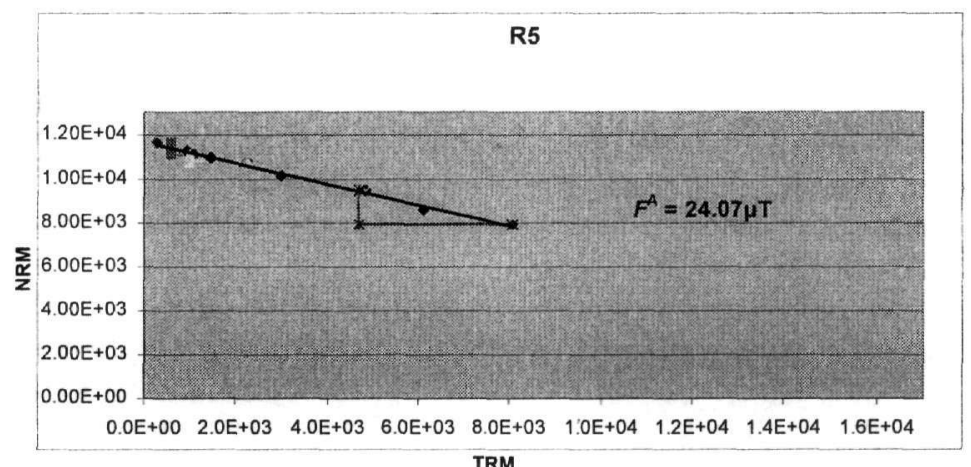

Figure 10. Arai plots of representative samples from R2 and R5 Roast beds as well as the paleointensity value as it is determined from the slope of the line.

\section{CONCLUSIONS}

The sampling technique we used and the usage of the resin helped us to treat safely our samples and consolidate the unconsolidated materials without any influences in their magnetization.

The distribution of the NRM and susceptibility demonstrate the presence of an older smelting activity. The recording of the last heating, which should have been shown in the upper part of our samples, is partly destroyed by the weathering of the surface as it is suggested from the rock magnetism analysis and the calculated paleointensities values.

The demagnetization reveals the presence of a stable component of magnetization carried by magnetite and heamatite as it arises from the rock magnetism experiments.

Finally, the roast-beds although they are very heterogeneous materials -and therefore difficult to study- seem to be suitable for an archaeomagnetic investigation since they are able to record a stable magnetization and consequently they can contribute to the study of the secular variation of the earth's magnetic field.acknowlegments

This study is part of the EU-funded AARCH project (HPRN-CT2002-00219). 


\section{REFERENCES}

Aitken M.J., Allsop A.L., Bussell G.D. \& Winter M.B. 1986. Paleointensity determination using the Thellier technique: reliability criteria. J. Geomagn. Geoelectr., 38, 1353-1363.

Chauvin A., Garcia Y., Lanos Ph. \& Laubenheimer F. 2000. Paleointensity of the geomagnetic field recovered on archaeomagnetic sited from France. Physics of the Earth and Planetary Interiors 120, 111-136.

Doonan R.C.P., Klemm S., Ottaway B.S., Sperl G. \& Weinek H. 1994. The east alpine Bronze Age copper smelting process: evidence from the Ramsau Valley, Eisenerz, Austria. Archaometry, Ankara.

Eibner C. 1982. Kupfererzbergbau in österreichs Alpen, in Südosteuropa zwischen 1600 and 1000 vor. Chr. In Hansel, B (eds). Prähistorisch Archäologie in Südosteuropa, 1: 399-408.

Hedley I.G. 2001. New directions in archaeomagnetism. Journal of Radioanalytical and Nuclear Chemistry, $247,3,663-672$.

Kono M. \& Tanaka H. 1984. Analysis of the Thellier's method of paleointensity determination 1: estimation of statistical errors. Journal of Geomagnetism and Geoelectricity 36, 267-284.

Kovacheva M. \& Toshkov A. 1994. Geomagnetic field variations as determined form Bulgarian archaeomagnetic data. Part I: The last 2000 years AD. Surveys in Geophysics 15, 673-701.

Kovacheva M., Jordanova N. \& Karloukovski V. 1998. Geomagnetic field variations as determined form Bulgarian archaeomagnetic data. Part II: The last 8000 years. Surveys in Geophysics 19, 431-460.

Marton P. 1996. Archaeomagnetic directions: The Hungarian calibration curve. In A. Morris \& D. Tarling (eds), Palaeomagnetism and Tectonics of the Mediterranean region. Geological Society Special publication N. 105:385-399.

Nagata T., Arai Y. \& Momose K. 1963. Secular variation of the geomagnetic total force during the last 5000 years. Journal of Geophysical Research 68, 5277-5281.

Schnepp E., Pucher R., Reinders J., Hambach U., Soffel H. \& Hedley J. 2004. A German catalogue of archaeomagnetic data. Geophysical Journal International, 157, 1.

Thellier E. \& Thellier O. 1959. Sur l'intensite du champ magnetique terestre dans le passé historique et geologique. Ann. Geophysiques 15, 285-376. 